\title{
CONSTRUÇÃO DE UM SISTEMA SIMPLES E COMPACTO DE RECIRCULAÇÃO D’ÁGUA SOB PRESSÃO PARA
} TROMPA D'ÁGUA

\author{
Dennis de Oliveira Imbroisi*, Carmen Silvia Tavares de Santana, Cleônia Roberta Melo Araújo, Wilson Ceciliano da Silva \\ e Cleylton Bezerra Lopes \\ Instituto de Química e Biotecnologia, Universidade Federal de Alagoas, Campus A. C. Simões, BR 104 - Norte, km 97, \\ 57072-970 Maceió - AL, Brasil
}

Recebido em 10/3/08; aceito em 10/7/08; publicado na web em 10/12/08

\begin{abstract}
CONSTRUCTION OF A SIMPLE AND COMPACT SYSTEM TO RECIRCULATE WATER UNDER PRESSURE USING A WATER-JET ASPIRATOR PUMP. Vacuum pumps are very useful in physical, chemical and biological experiments. In this communication it is described the design of a compact and low cost water recirculating system employing a water-jet aspirator pump as the vacuum source. The system requires only a water pump, water-jet aspirator pump, commercial PVC water tubes and a drain connection.
\end{abstract}

Keywords: water-jet aspirator pump; water recirculating system; vacuum.

\section{INTRODUÇÃO}

A importância do vácuo nos laboratórios de física, química e biologia é indiscutível. Nestes laboratórios, ele encontra as mais variadas aplicações: como isolante, na filtração por sucção, na destilação, na sublimação e na secagem entre outros usos. ${ }^{1}$ Sem dúvida alguma, o dispositivo mais simples empregado para a obtenção de pressões reduzidas é a trompa d'água. O vácuo que se pode obter é limitado à pressão de circulação d'água através da canalização e de sua temperatura. Teoricamente, uma trompa d'água eficiente reduz a pressão do sistema a um valor igual à pressão de vapor d'água na temperatura em que ela se encontra na fonte de suprimento. Na prática, isto não é atingido devido à entrada de ar na aparelhagem.

A pressão de vapor d'água varia consideravelmente com sua temperatura e, conseqüentemente, o vácuo obtido em uma trompa d'água também vária. A Tabela 1 apresenta a variação da pressão de vapor versus a temperatura d'água. ${ }^{2}$

Tabela 1. Temperatura e pressão de vapor d'água

\begin{tabular}{lc}
\hline Temperatura d'água $\left({ }^{\circ} \mathrm{C}\right)$ & Pressão de vapor d'água $(\mathrm{mm} \mathrm{Hg})$ \\
\hline 5 & 6,543 \\
10 & 9,209 \\
15 & 12,788 \\
20 & 17,535 \\
25 & 23,756 \\
30 & 31,824 \\
35 & 42,175 \\
\hline
\end{tabular}

Obter água sob alta pressão é o fator limitante para o bom funcionamento de uma trompa d'água. $\mathrm{O}$ banho de recirculação de água, uma caixa d'água acoplada a uma bomba d'água, é uma boa solução para este problema. Esta solução esbarra no tamanho e na dificuldade em transportar o sistema de um lado para o outro do laboratório. A

*e-mail: doi@qui.ufal.br necessidade de reduzir o tamanho dos banhos de recirculação de água, para que possam ser transportados com facilidade dentro do laboratório e usados dentro de uma capela de exaustão, nos levou a construir um sistema de recirculação de água sob pressão simples, compacto e de baixo custo com conexões em PVC rígido de água e esgoto. Este sistema já vem sendo usado em nosso laboratório há mais de 15 anos e em laboratórios em diferentes estados do país. A eficiência deste sistema nos motivou a escrever a presente nota técnica.

\section{DESCRIÇÃO}

O sistema de recirculação d'água foi todo construído usando-se uma bomba d'água de 1/4 cv e conexões de PVC rígido, (Figura 1 e Tabela 2). Todos os itens podem ser comprados em casas comerciais de material de construção (Tabela 2). A sua montagem é bastante simples, exigindo apenas uma furadeira e uma chave de fenda como ferramentas. Assim, qualquer pessoa pode montá-lo, sem o auxílio de encanador.

A madeira usada para construir o chassi do sistema deve ser adquirida em uma madeireira local. ${ }^{3} \mathrm{O}$ chassi foi feito com uma tábua de $70 \mathrm{~cm}$ de comprimento por $20 \mathrm{~cm}$ de largura e $3 \mathrm{~cm}$ de espessura (22). Os pés (23) são feitos de dois pedaços de 5 x 20 x $3 \mathrm{~cm}$ da mesma madeira. Cada pé foi afixado ao chassi por meio de dois parafusos. Para corrigir a altura entre a bomba d'água (1) e a tampa (6) do "T" (5), foi usado um pedaço de madeira (21) de $20 \times 20 \times 4 \mathrm{~cm}$ fixado ao chassi por quatro parafusos. Inicialmente, a bomba d'água deve ser fixada ao chassi e a partir deste ponto o sistema deve ser construído. Entre a bomba d'água e o chassi do sistema foi colocado um pedaço de borracha (24) de $20 \times 20 \times 0,4$ $\mathrm{cm}$ para diminuir a vibração e, conseqüentemente, o barulho. Dois outros pedaços de borracha (25) com 3 x 20 x 0,4 cm foram colados aos pés com a mesma finalidade.

As conexões soldáveis em PVC rígido tiveram suas superfícies levemente lixadas e uma camada generosa de cola foi passada, sendo as peças unidas rapidamente. As conexões rosqueáveis foram recobertas por uma fina camada de veda-rosca, fita de teflon, antes de uní-las. Os tubos de PVC só devem ser cortados durante a montagem do sistema, visto que pequenas variações podem ocorrer de acordo com a altura da bomba d'água, da marca das conexões e da trompa d'água usadas. 
Tabela 2. Lista de itens usados para montagem do sistema de recirculação d'água com trompa d'água

\begin{tabular}{|c|c|c|c|}
\hline Item & Quantidade & Discriminação dos Materiais & Preço $(\mathrm{R} \$)$ \\
\hline 1 & 1 un & Bomba d'água $1 / 4 \mathrm{cv}$ & 250,00 \\
\hline 2 & 1 un & Interruptor & 3,02 \\
\hline 3 & 1 un & Plugue & 1,76 \\
\hline 4 & $1,5 \mathrm{~m}$ & Fio elétrico flexível duplo $2,5 \mathrm{~mm}$ & 3,00 \\
\hline 5 & 2 un & “T” de inspeção 100 mm & 44,20 \\
\hline 6 & 2 un & Cap 100 mm & 8,50 \\
\hline 7 & $1 \mathrm{~m}$ & *Tubo de PVC $100 \mathrm{~mm}$ & 4,00 \\
\hline 8 & 1 un & $\begin{array}{l}\text { Adaptador soldável com anel de } \\
\text { vedação para caixa d'água 1/2' }\end{array}$ & 5,54 \\
\hline 9 & 1 un & $\begin{array}{l}\text { Adaptador soldável com anel de } \\
\text { vedação para caixa d'água 3/4' }\end{array}$ & 6,86 \\
\hline 10 & 1 un & União soldável 3/4' & 4,05 \\
\hline 11 & 3 un & $\begin{array}{l}\text { Adaptador soldável curto com } \\
\text { bolsa e rosca 3/4' }\end{array}$ & 1,35 \\
\hline 12 & $1 \mathrm{~m}$ & *Tubo de PVC 3/4' & 2,00 \\
\hline 13 & 1 un & $\begin{array}{l}\text { Bucha de redução soldável curta } \\
\text { 3/4, } / 1 / 2^{\prime}\end{array}$ & 0,24 \\
\hline 14 & $1 \mathrm{~m}$ & Tubo de PVC 1/2' & 1,00 \\
\hline 15 & 1 un & Curva longa $90^{\circ}$ de $1 / 2^{\prime}$ & 0,80 \\
\hline 16 & 1 un & $\begin{array}{l}\text { Luva soldável com bucha de rosca } \\
\text { de latão } 1 / 2\end{array}$ & 2,82 \\
\hline 17 & 1 un & Torneira plástica $1 \frac{2}{2}$ para jardim & 2,34 \\
\hline 18 & 2 un & Braçadeira & 3,60 \\
\hline 19 & $1 \mathrm{~m}$ & Mangueira & 2,10 \\
\hline 20 & 1 un & Trompa d'água & 25,00 \\
\hline 21 & 1 un & Madeira $20 \times 20 \times 5 \mathrm{~cm}$ & \multirow{3}{*}{20,00} \\
\hline 22 & 1 un & Madeira $70 \times 20 \times 3 \mathrm{~cm}$ (chassis) & \\
\hline 23 & 2 un & Madeira 5 x 20 x 3 cm (pés) & \\
\hline 24 & 1 un & $\begin{array}{l}\text { Tapete de Borracha } 20 \text { x } 20 \text { x 0,4 } \\
\text { cm (apoio para bomba d'água) }\end{array}$ & \multirow{2}{*}{12,00} \\
\hline 25 & 2 un & $\begin{array}{l}\text { Tapete de borracha do } 3 \times 20 \text { x 0,4 } \\
\text { cm (pé) }\end{array}$ & \\
\hline & 1 un & Adesivo para PVC $75 \mathrm{~g} *$ & 2,19 \\
\hline & 12 un & Parafuso para bucha $8 \mathrm{~mm} *$ & 2,50 \\
\hline & 1 un & Lixa* & 0,25 \\
\hline & \multirow[t]{2}{*}{1 un } & Veda rosca* & 2,50 \\
\hline & & TOTAL & 411,62 \\
\hline
\end{tabular}

* Itens necessários para a montagem do sistema.

Os furos nos "T" de inspeção (5) para afixar os adaptadores de caixa d'água (8) e (9) e na "cap" (6), para passar a trompa d'água (20), foram feitos com brocas de diâmetro adequado, broca ou serra copo. Os furos com diâmetros grandes também podem ser feitos desenhando-se um círculo de tamanho adequado na peça a ser furada. Então, com o auxílio de uma broca fina faz-se uma série de pequenos furos, em cruz, cobrindo todo o seu perímetro até que, com o auxílio de uma chave de fenda, seja possível soltar o pedaço desejado para abrir o buraco. O pedaço de tubo de $100 \mathrm{~mm}$ (7), usado para unir o

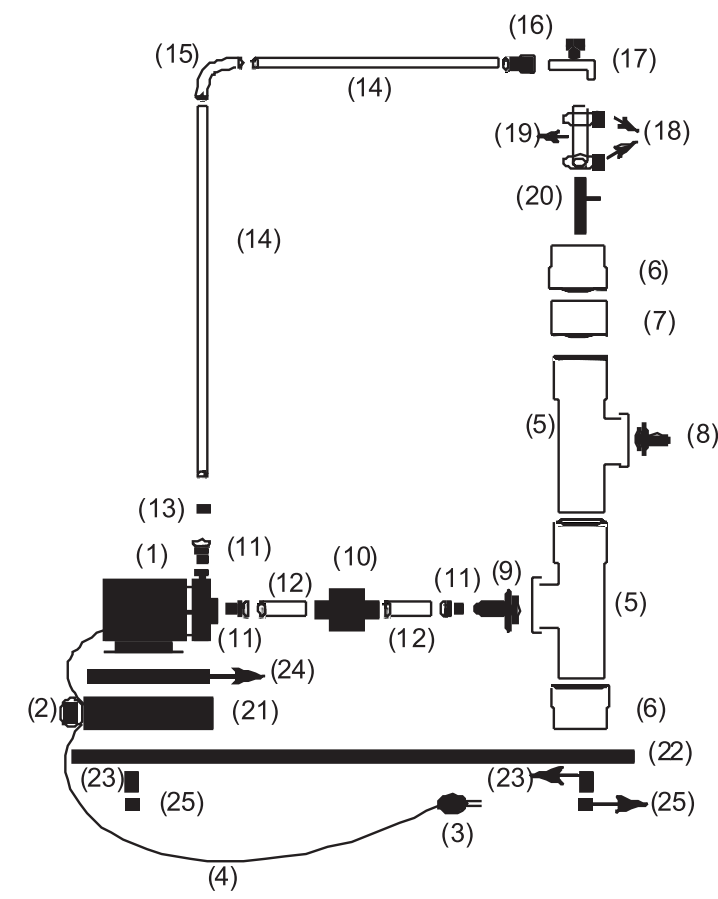

Figura 1. Diagrama mostrando as partes necessárias para construção do sistema de recirculação d'água

“cap" (6) com o "T" (5), só deve ser colado a (6), já que este conjunto de peças [(7)+(6)] serve como uma tampa que, na eventualidade de se aspirar substâncias tóxicas ou sólidas, pode ser removida para lavar o reservatório d'água. A maneira mais simples e barata de ligar a trompa d'água ao sistema de recirculação é através do uso de uma torneira (17). Ela pode ser substituída por conexões feitas sob medida para a trompa d'água escolhida, por um torneiro mecânico.

$\mathrm{O}$ aumento da temperatura d'água devido ao seu atrito com as paredes do sistema, por causa da velocidade de recirculação, tem como conseqüência uma diminuição na capacidade da trompa d'água em fazer vácuo e o amolecimento das conexões de PVC. Se a temperatura aumentar muito, pode haver vazamentos e até descolamento das partes. Este problema é facilmente contornado circulando água à temperatura ambiente através do sistema. Para isto, uma mangueira ligada à rede d'água é conectada ao sistema através do mesmo furo por onde passa a trompa d'água e um outro pedaço de mangueira é ligado ao adaptador de caixa d'água (8), que funciona como um "ladrão", para escoamento automático do excesso de água quente.

O problema de refrigeração do sistema de recirculação, de consumo e contaminação de um grande volume d'água, uma trompa d'água ligada diretamente a uma torneira consome até $500 \mathrm{~L} / \mathrm{h}$, pode ser solucionado com a instalação de um Tê de $20 \mathrm{~mm}$ (26), soldável com bucha de latão na bolsa central $(\mathrm{R} \$ 4,50)$, e outra torneira de jardim, Figura 2. A esta torneira é ligada uma mangueira que por sua vez é ligada a uma serpentina, feita enrolando-se $5 \mathrm{~m}$ de tubo de cobre flexível de $6 \mathrm{~mm}$ (R\$ 6,50 por m) em volta do tubo de PVC de $100 \mathrm{~mm}$. Na saída desta serpentina é conectada outra mangueira de retorno da água ao sistema de recirculação. Esta mesma água pode ser aproveitada, antes de voltar para o sistema de recirculação d'água, para resfriar como, por exemplo, um sistema de destilação. A qualidade desta água pode ser monitorada visualmente e trocada quando necessário. Com esta modificação no sistema de recirculação d'água somente um pequeno volume de água é contaminado, volume de água recirculante em torno de 2-3 L, o que baixa o custo de sua descontaminação. 


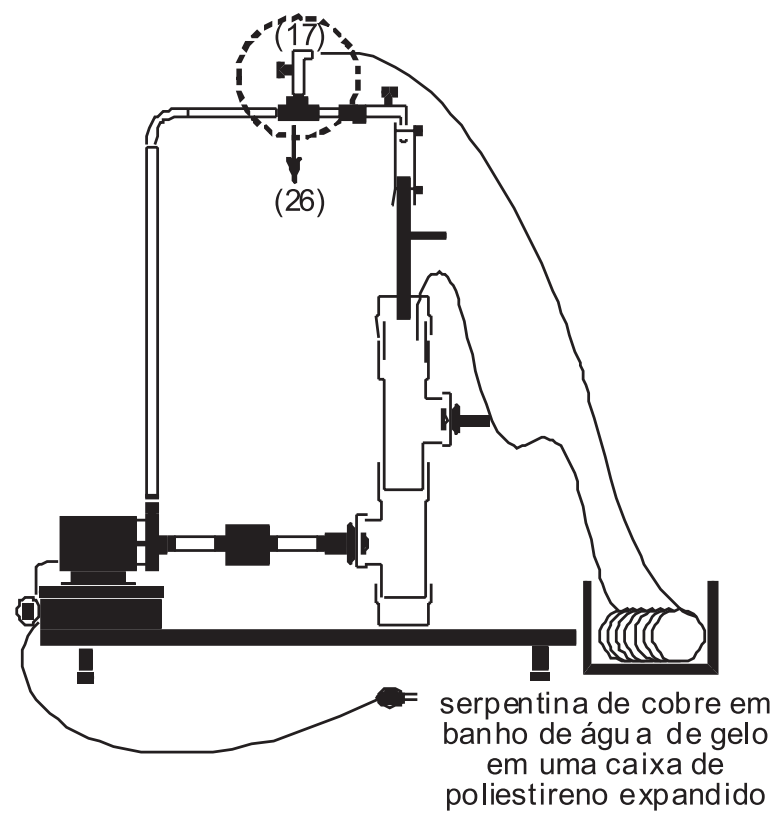

Figura 2. Sistema de recirculação d'água modificado

\section{CONCLUSÃO}

A montagem do sistema de recirculação d'água descrito (Figura 1) requer somente partes encontradas em qualquer casa de material de construção, não exigindo uma mão-de-obra ou mercado especializado. Este sistema mostrou-se bastante eficiente, atendendo todas as nossas expectativas. Em nosso laboratório temos três destes sistemas, sendo dois usados em evaporadores rotativos e um em filtrações, destilações e remoção de solvente de misturas reacionais.

\section{AGRADECIMENTOS}

Ao CNPq, à Capes, à Fapeal e ao Banco do Nordeste pelo suporte financeiro. Agradecemos as valiosas sugestões do assessor da editoria.

\section{REFERÊNCIAS E NOTAS}

1. Amarego, W. L. F.; Perrin, D. D.; Purification of Laboratory Chemical, $4^{\text {th }}$ ed., Butterworth Heinemann, Reed Educational and Professional Publishing Ltd.: Oxford, 1997, cap 1.

2. Lide, D. R.; CRC Handbook of Chemistry and Physics, $87^{\text {th }}$ ed., CRC Press: Florida, 2006.

3. Deve ser escolhida uma madeira de lei (jatobá, maçaranduba, etc) para construção do chassi do sistema de recirculação d'água. 